\title{
Nörolojik Hastalıklara Sahip Bireylerin ve Bakım Verenlerinin Aktivite Yönünden Tedavi Hedeflerine Bakışı
}

The Individuals with Neurological Diseases and Their Caregivers' View of the Treatment Goals in Terms of Activity

\author{
Özge Buket CESiM ${ }^{1}$, Burcu Semin AKEL ${ }^{2}$, Çiğdem ÖKSÜZ ${ }^{2}$ \\ ${ }^{1}$ Erg., Hacettepe Üniversitesi, Sağlık Bilimleri Fakültesi, Ergoterapi Bölümü, Araştırma Görevlisi, Ankara \\ 2 Doç. Dr., Hacettepe Üniversitesi, Sağlık Bilimleri Fakültesi, Ergoterapi Bölümü, Öğretim Üyesi, Ankara
}

\section{Öz}

\begin{abstract}
Amaç: Nörolojik hastalıklara sahip bireylerin ve bakım verenlerinin aktivite yönünden tedavi hedefleri arasındaki uyumu incelemektir. Gereç ve Yöntem: Araştırmaya nörolojik hastalığa sahip 18-65 yaş arası 46 birey (26 erkek, 20 kadın) dahil edildi. Hasta ve bakım verenin aktivite yönünden tedavi hedefleri Kanada Aktivite Performans Öıçümü (KAPÖ) ile değerlendirildi. Hastaların ve bakım verenlerin tedavi hedefleri, KAPÖ kendine bakım, üretkenlik ve serbest zaman aktiviteleri performans alanlarına göre kayıt edildi. Hastaların belirttiği aktivitelerin bakım veren tarafından söylenen aktivitelerle uyumu yüzde olarak

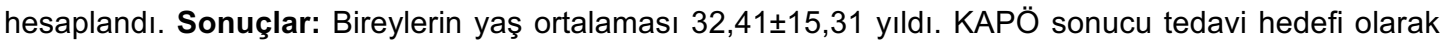
hem hastalar hem de bakım verenler ilk sırada kendine bakım aktivitelerini belirttiler. Hastalar bakım verenlerden daha fazla üretkenlik aktiviteleri belirtirken; daha az serbest zaman aktiviteleri belirttiler. Bireyler ve bakım verenler arasındaki tedavi hedeflerinin uyumu $\% 26$ olarak belirlendi. Kadın hastalar ve bakım verenleri arasındaki tedavi hedeflerinin uyum ortalaması $\% 29$, erkek hastalar ve bakım verenleri arasındaki ise \%26’ydı. Tartışma: Sonuçta, nörolojik hastalıklara sahip hastaların ve bakım verenlerinin aktivite performans alanlarından kendine bakım, üretkenlik ve serbest zaman aktivitelerine yönelik farklı aktiviteler belirttiği ve tedavi hedefleri arasındaki uyumun düşük olduğunu görülmüştür. Bu, bakım verenlerin hastalara göre iyileşmeye yönelik farklı beklentiler içerisinde olabileceğini göstermektedir.
\end{abstract}

Anahtar Kelimeler: Nöroloji; Bakım Veren; Aktivite.

\section{ABSTRACT}

Purpose: The aim is to examine compatibility between treatment goals of individuals with neurological diseases and caregivers in terms of activity. Material and Methods: 46 individuals (26 males, 20 females) with a neurological disease, aged 18-65 years were included in the study. Treatment goals of patients and caregivers in terms of activity were assessed by Canadian Occupational Performance Measure (COPM). Patients and caregivers' treatment goals were recorded according to performance areas of COPM which are self-care, productivity and leisure time activities. The compatibility of activities reported by caregivers and the ones that are mentioned by patients were calculated in percentages. Results: Average age of individuals was $32.41 \pm 15.31$ years. As a result of COPM, both patients and caregivers firstly specified self-care activities as a treatment goal. Patients stated more productivity activities and less free time activities than caregivers. Compatibility of treatment goals between individuals and caregivers was $26 \%$. Mean compatibility of treatment goals between female patients and caregivers was $29 \%$, between male patients and caregivers was $26 \%$. Conclusion: Results show that caregivers and patients with neurological diseases report different activities for self-care, productivity, and leisure-time activities in areas of occupational performance, and there is low compatibility between treatment goals. This suggests that caregivers and patients may have different expectations about the recovery.

Key Words: Neurology; Caregiver; Activity.

Sorumlu Yazar (Corresponding Author): Özge Buket Cesim e-mail: obuketcesim@hacettepe.edu.tr.

ORCID ID: 0000-0001-5127-4181

Geliş Tarihi (Received): 13.03.2018; Kabul Tarihi (Accepted): 23.10.2018

Bu çalışma 31 Haziran-1, 2 Mayıs 2017 tarihlerinde, İstanbul' da 'Ergoterapi ve Rehabilitasyon' Uluslararası Kapanış Kongresi'nde poster olarak sunulmuştur. 
Nörolojik hastalıklar sinir sistemini etkileyen; paralizi, rijidite veya koordineli olmayan hareketler sebebiyle fiziksel fonksiyonlarda limitasyona, dikkat ve hafıza problemleri gibi kognitif bozukluklara, iç görü ve öfke kontrol yokluğu gibi davranışsal problemlere ve konuşma problemleri nedeniyle iletişim bozukluklarına yol açabilen hastalıklardır. Fonksiyonel ve kognitif limitasyonlar sebebiyle nörolojik hastalıklara sahip bireylerin giyinme, yemek yeme gibi birçok günlük yaşam aktiviteleri (GYA) etkilenebilmektedir. Bozukluklar nedeniyle uzun dönemde katılım sorunu yaşayan nörolojik hasta grubunda, tedavi hedefleri arasında gya katılımı yer almaktadır (Aarli, 2006).

Bakım veren, hastanın bakımında en çok görev alan ya da primer olan kişi olarak tanımlanmaktadır (Aoun ve ark, 2012). Nörolojik hastalıklara sahip bireylerdeki problemlerin karmaşıkığı, bakım verenlerin birçok komponenti içeren destek stratejilerine intiyaç duymalarına sebep olmaktadır (Mitchell ve ark, 2015). Nörolojik hastaların limitasyonları nedeniyle bakım veren 15 saate kadar bireyin katıımına yönelik yaklaşımlarda bulunmakta ve GYA' larına yardım etmektedir (Aoun ve ark, 2012). İyileşmede bakım vereni içeren sosyal çevrenin önemli olduğu söylenmektedir. Bundan dolayı birçok araştırma; bakım veren eğitimi, evde bakım servisleri gibi rehabilitasyon yaklaşımlarını içeren bütüncül bir tedavinin bakım verenin stres ve depresyon seviyesinde azalma sağladığını ve yükünü azaltığını belirtmektedir (Brodaty \& Donkin, 2009; Gitlin, Corcoran, Winter, Boyce, \& Hauck, 2001; Graff ve ark, 2006; Mitchell ve ark, 2015).

Nörolojik hastalıklara sahip bireyler ve bakım verenlerinin tedavi ve bakım konusunda -özellikle bakım verenin yük seviyesi artıkça- aynı görüş ve inanışlara sahip olmadığı literatürde belirtilmektedir. Bundan dolayı hasta ve bakım verenin tedavi hedefleri farklı olabilir (Bolmsjö \& Hermerén, 2003; Sands, Ferreira, Stewart, Brod, \& Yaffe, 2004). Nörolojik rehabilitasyonda tedavi hedefleri planlamak, önemli bir prosedür olarak kabul edilmektedir. Doğru tedavi hedefleri oluşturmanın birçok avantajı bulunmaktadır. Hedefler, kişi merkezli rehabilitasyon yaklaşımını sağlayarak hastanın tedaviye aktif katıımını gerçekleştirir ve rehabilitasyon süreciyle ilişkili tatmini artırır. Tedavi hedefleri oluşturulurken bakım verenler de sürece dahil olmalı ve katkı verme konusunda cesaretlendirilmelidir (Donnelly ve ark, 2004; Mcmillan \& Sparkes, 1999). Bu doğrultuda çalışmamızın amacı nörolojik hastalıklara sahip bireyler ve bakım verenlerinin aktivite yönünden tedavi hedeflerini saptamak ve bu iki grup arasındaki tedavi hedeflerinin uyumunu incelemektir.

\section{GEREÇ VE YÖNTEM}

Retrospektif olarak planlanan çalışmaya Hacettepe Üniversitesi, Sağlık Bilimleri Fakültesi, Ergoterapi Bölümü, Erişkin Ergoterapi Ünitesine 2014-2017 yılları arasında başvuran farklı nörolojik hastalıklara sahip 46 hasta ve onların bakım verenleri alındı. Çalışmada Helsinki Deklarasyonu esas alındı. Çalışmaya dahil olan tüm hastalara Veri Kullanımı Onam Formu imzalatıldı.

Çalışmaya dahil edilme kriterleri hastalar için, nörolojik bir hastalık tanısı almış olmak ve 18-65 yaş arasında olmak; bakım verenler için, 18 yaş üstü olmak, hastayla yaşamak ve birincil bakım veren olmak olarak belirlendi. Çalışmadan hariç tutulma kriterleri hastalar için; sistemik, ortopedik ve/veya psikiyatrik hastalığa sahip olmak, birden fazla nörolojik hastalık geçirmiş olmak, kognitif problemi olmak (Standardize Mini Mental Durum Değerlendirmesi Testi'nden 23 ve altı puan almak) olarak belirlendi.

\section{Kişilerin Değerlendirilmesi}

Hastaların yaş, cinsiyet, tanılarını içeren sosyodemografik bilgileri alındı. Yazarlar tarafından hastalara ve bakım verenlerine Kanada Aktivite Performans Ölçümü (KAPÖ) değerlendirmesi uygulandı. Hem hastaların hem de bakım verenlerin değerlendirmesi hastaların ilk seanslarında yapıldı. Hastaların ve bakım verenlerin KAPÖ sonucu tedavi hedefleri, KAPÖ' nün kendine bakım, üretkenlik ve serbest zaman aktiviteleri olan performans alanlarına göre kayıt edildi.

\section{Kanada Aktivite Performans Ölçümü (KAPÖ)}

Kanada Aktivite Performans Ölçümü, kişilerin yaralanmaları sonucu problem yaşadıkları aktiviteleri belirlemek ve aktivite performans problemlerinin zamanla değişimini saptamak amacıyla oluşturulmuş bireyselleştirilmiş bir ölçümdür. KAPÖ, 1990 yılında Law ve arkadaşları tarafından geliştirilmiştir. Uygulaması 20-40 dakika arasında değişmektedir. Beş adımdan oluşmaktadır. İlk adımda bireylerin aktivite performans alanlarını oluşturan kendine bakım, üretkenlik ve serbest zaman aktiviteleri ile ilgili sorular sorularak bireyle görüşme yapılır ve problem yaşanılan aktiviteler belirlenir. İkinci adımda bireylerden belirlenmiş her aktivitenin önemine 1-10 arası bir puan vermesi istenir ( 1 = hiç önemli değil, $10=$ çok önemli). Üçüncü adımda beş en önemli aktivite not edilir ve bireyden bu aktivitelerin performans ve tatminlerini 1-10 arası puanlaması istenir. Aktivitelerdeki performans ve tatmin puanları toplanarak seçilen problemli aktivitelerin sayısına bölünür ve toplam puan hesaplanır. Dördüncü adım tekrar değerlendirmedir. Beşinci adım takip aşamasıdır. Yeni problemli aktiviteler belirlenir ve buna göre tedavinin devamlılığı için plan yapılır. Çalışmamızda KAPÖ' nün birinci ve ikinci adımı ve 
üçüncü adımdaki beş en önemli aktivitenin not edilmesi kısmı uygulanmıştır. (Law ve ark, 1990; Tuntland, Aaslund, Langeland, Espehaug, \& Kjeken, 2016)

\section{İstatistiksel Analiz}

Araştırma verilerinin istatistiksel analizlerinde SPSS 21 istatistik programı kullanıldı. Sosyodemografik verilerin tanımlayıcı istatistikleri ortalama, standart sapma, minimum ve maksimum olarak hesaplandı. KAPÖ aktivite performans alanlarına göre belirlenen aktivite hedefleri hem hasta hem bakım veren için yüzde (\%) olarak ifade edildi. Hastaların belirttiği aktivitelerin bakım veren tarafından söylenen aktivitelerle uyumu \% olarak hesaplandı. Hasta ve bakım vereni tarafından söylenen tüm aktivitelerin aynı olması \%100 uyum, tamamen farklı olması $\% 0$ uyum olarak puanlandı. Bütün aktiviteler için uyum, tanımlayıcı istatistiklerden ortalama, standart sapma, minimum ve maksimum olarak hesaplandı.

\section{SONUÇLAR}

Çalışmaya dahil edilen 46 hastadan 20'si kadın (\%44), 26'sı erkektir (\%56). Çalışmaya dahil edilen hastaların yaş ortalaması 32,41 \pm 15,31 yıldır. Hastaların 15'i serebral palsi (\%33), 14'ü inme (\%30), 9'u travmatik beyin yaralanması (\%20) ve 8'i demans, mental retardasyon gibi diğer nörolojik hastalık (\%17) tanılarına sahiptir.

KAPÖ sonucu tedavi hedefi olarak hem hastalar hem de bakım verenler ilk sıraya kendine bakım aktivitelerini koydular (sırasıyla 48 ve 33 aktivite). Hastalar bakım verenlerden daha fazla üretkenlik aktiviteleri belirtirken (sırasıyla 25 ve 10 aktivite); daha az serbest zaman aktiviteleri belirttiler (sırasıyla 14 ve 18 aktivite). KAPÖ' ye göre hastaların ve bakım verenlerin aktivite yönünden tedavi hedefleri ve her bir aktiviteyi belirten kişilerin sayıları Tablo 1 ve 2' de gösterildi.

Tablo 1: KAPÖ' ye göre hastaların aktivite yönünden tedavi hedefleri ve aktiviteleri belirten kişi sayıları

\begin{tabular}{|c|c|c|c|}
\hline \multirow[t]{2}{*}{ KAPÖ Aktivite Performans Alanları } & \multirow{2}{*}{$\begin{array}{l}\text { KAPÖ Sonucu Hastaların } \\
\text { Tedavi Hedefleri }\end{array}$} & \multicolumn{2}{|c|}{ Hastalar $(n=46)$} \\
\hline & & $\mathbf{n}$ & $\%$ \\
\hline \multirow{9}{*}{$\begin{array}{l}\text { 1.Kendine Bakım } \\
\text { - Kişisel Bakım (giyinme, banyo, beslenme, hijyen vb.) }\end{array}$} & & & \\
\hline & Yemek Yemek & 9 & 19,5 \\
\hline & Giyinmek & 9 & 19,5 \\
\hline & Tırnak Kesmek & 4 & 8,6 \\
\hline & Banyo Yapmak & 3 & 6,5 \\
\hline & Saçları Toplamak & 3 & 6,5 \\
\hline & Makyaj Yapmak & 2 & 4,3 \\
\hline & Tuvalet Hijyeni & 2 & 4,3 \\
\hline & Diş Fırçalamak & 1 & 2,1 \\
\hline - Fonksiyonel Mobilite (ev içi ve dışı transferler) & Okula Gitmek & 3 & 6,5 \\
\hline \multirow[t]{2}{*}{-Toplumsal Başarı (ulaşım, finans, alışveriş yapma vb.) } & Araba kullanmak & 9 & 19,5 \\
\hline & Alışveriş yapmak & 3 & 6,5 \\
\hline \multirow{5}{*}{$\begin{array}{l}\text { 2.Üretkenlik } \\
\text { - Maaşlı/Maaşsız İş (iş bulma/arama, gönüllü çalışma) }\end{array}$} & & & \\
\hline & Yazı yazmak & 8 & 17,3 \\
\hline & İşe dönmek & 7 & 15,2 \\
\hline & Bilgisayar Kullanmak & 2 & 4,3 \\
\hline & Yemek yapmak & 5 & 10,8 \\
\hline \multirow{3}{*}{$\begin{array}{l}\text { - Ev İşi Yönetimi (temizlik, çamaşır yıkama, yemek } \\
\text { pişirme vb.) }\end{array}$} & Bulaşık yıkamak & 1 & 2,1 \\
\hline & Çocuğuna bakmak & 1 & 2,1 \\
\hline & Evi temizlemek & 1 & 2,1 \\
\hline - Oyun/Okul (Ev Ödevi Yapma, Oyun Oynama vb.) & - & - & - \\
\hline \multicolumn{4}{|l|}{ 3.Serbest Zaman } \\
\hline -Sessiz Rekreasyon (Hobiler, el işi, okuma vb.) & - & - & - \\
\hline \multirow[t]{6}{*}{-Aktif Rekreasyon (Spor, seyehat vb.) } & Dışarı çıkmak & 3 & 6,5 \\
\hline & Futbol oynamak & 3 & 6,5 \\
\hline & Enstrüman çalmak & 3 & 6,5 \\
\hline & Egzersiz yapmak & 1 & 2,1 \\
\hline & Yüzmek & 1 & 2,1 \\
\hline & Sinema/tiyatroya gitmek & 1 & 2,1 \\
\hline \multirow[t]{2}{*}{-Sosyalizasyon (ziyaret, partiler, telefon görüşmesi vb.) } & Bilardo Oynamak & 1 & 2,1 \\
\hline & Arkadaşlarıyla görüşmek & 1 & 2,1 \\
\hline
\end{tabular}

n: kişi sayısı, \%: yüzde 
Tablo 2. KAPÖ’ ye göre bakım verenlerin aktivite yönünden tedavi hedefleri ve aktiviteleri belirten kişi sayıları

\begin{tabular}{|c|c|c|c|}
\hline \multirow{2}{*}{ KAPÖ Aktivite Performans Alanları } & \multirow{2}{*}{$\begin{array}{l}\text { KAPÖ Sonucu Bakım } \\
\text { Verenlerin Tedavi Hedefleri }\end{array}$} & \multicolumn{2}{|c|}{ Bakım verenler $(n=46)$} \\
\hline & & $\mathbf{n}$ & $\%$ \\
\hline \multirow{7}{*}{$\begin{array}{l}\text { 1.Kendine Bakım } \\
\text { - Kişisel Bakım (giyinme, banyo, beslenme, } \\
\text { hijyen vb.) }\end{array}$} & & & \\
\hline & Giyinmek & 9 & 19,5 \\
\hline & Yemek yemek & 8 & 17,3 \\
\hline & Banyo yapmak & 5 & 10,8 \\
\hline & Tırnak kesmek & 4 & 8,6 \\
\hline & Traş olmak & 2 & 4,3 \\
\hline & Makyaj yapmak & 1 & 2,1 \\
\hline $\begin{array}{l}\text { - Fonksiyonel Mobilite (ev içi ve dışı } \\
\text { transferler) }\end{array}$ & Okula Gitmek & 1 & 2,1 \\
\hline $\begin{array}{l}\text {-Toplumsal Başarı (ulaşım, finans, alışveriş } \\
\text { yapma vb.) }\end{array}$ & Araba kullanmak & 3 & 6,5 \\
\hline \multirow{4}{*}{$\begin{array}{l}\text { 2.Üretkenlik } \\
\text { - Maaşlı/Maaşsız İş (iş bulma/arama, gönüllü } \\
\text { çalışma) }\end{array}$} & & & \\
\hline & İşe dönmek & 3 & 6,5 \\
\hline & Yazı yazmak & 3 & 6,5 \\
\hline & Bilgisayar Kullanmak & 1 & 2,1 \\
\hline \multirow[t]{2}{*}{$\begin{array}{l}\text { - Ev İşi Yönetimi (temizlik, çamaşır yıkama, } \\
\text { yemek pişirme vb.) }\end{array}$} & Dikis dikmek & 1 & 2,1 \\
\hline & Çocuğuna bakmak & 1 & 2,1 \\
\hline \multirow{2}{*}{$\begin{array}{l}\text { - Oyun/Okul (Ev Ödevi Yapma, Oyun } \\
\text { Oynama vb.) }\end{array}$} & Yemek yapmak & 1 & 2,1 \\
\hline & - & - & - \\
\hline $\begin{array}{l}\text { 3.Serbest Zaman } \\
\text {-Sessiz Rekreasyon (Hobiler, el işi, okuma } \\
\text { vb.) }\end{array}$ & Kitap okumak & 1 & 2,1 \\
\hline \multirow[t]{3}{*}{-Aktif Rekreasyon (Spor, seyehat vb.) } & Dışarı çıkmak & 5 & 10,8 \\
\hline & Egzersiz yapmak & 1 & 2,1 \\
\hline & Enstrüman çalmak & 1 & 2,1 \\
\hline \multirow{2}{*}{$\begin{array}{l}\text {-Sosyalizasyon (ziyaret, partiler, telefon } \\
\text { görüşmesi vb.) }\end{array}$} & Arkadaş ve akrabalarla görüşmek & 9 & 19,5 \\
\hline & Telefon kullanmak & 1 & 2,1 \\
\hline
\end{tabular}

Hastaların en çok belirttiği beş aktivite yemek yemek $(\% 19,5)$, giyinmek $(\% 19,5)$, araba kullanmak $(\% 19,5)$, yazı yazmak $(\% 17,3)$ ve işe dönmek $(\% 15,2)$ olarak belirlendi. Bakım verenlerin en çok belirttiği beş aktivite arkadaş ve akrabalarla görüşmek $(\% 19,5)$, giyinmek $(\% 19,5)$, yemek yemek $(\% 17,3)$, banyo yapmak $(\% 10,8)$ ve dışarı çıkmak $(\% 10,8)$ idi.

Hastalar ve bakım verenler arasındaki tedavi hedeflerinin uyumu \%0-100 arasında değişiklik gösterdi. 20 hasta ve bakım veren tamamen farklı aktiviteleri tedavi hedefi olarak belirtirken (aktivite uyumu=\%0), 4 hasta ve bakım veren tamamen aynı aktiviteleri tedavi hedefi olarak belirtti (aktivite uyumu=\%100). Hastalar ve bakım verenler arasındaki tedavi hedeflerinin uyum ortalaması \%28 olarak bulundu. Kadın hastalar ve onların bakım verenleri arasındaki tedavi hedeflerinin uyum ortalaması \%29, erkek hastalar ve bakım verenleri arasındaki tedavi hedeflerinin uyum ortalaması \%26 idi (Tablo 3).

Tablo 3. Hasta ve bakım verenlerin tedavi hedefleri arasındaki uyum

\begin{tabular}{llll}
\hline & Toplam & Kadın & Erkek \\
\hline Ortalama + standart sapma & $\% 28 \pm 4,71$ & $\% 29 \pm 8,20$ & $\% 26 \pm 5,60$ \\
\hline Minimum & 0 & 0 & 0 \\
\hline Maksimum & 100 & 100 & 100 \\
\hline
\end{tabular}

\section{TARTIŞMA}

Çalışmamız sonucu, nörolojik hastalıklara sahip hastaların ve bakım verenlerinin aktivite performans alanlarından kendine bakım, üretkenlik ve serbest zaman aktivitelerine yönelik farklı aktiviteler belirttiği ve tedavi hedefleri arasındaki uyumun düşük olduğu görülmektedir. Bu da bakım verenlerin hastalara göre iyileşmeye yönelik farklı beklentiler içerisinde olabileceğini göstermektedir. Benzer olarak, Demir ve arkadaşları inmeli bireylerle yaptıkları çalışmada hastaların tedaviye yönelik önceliklerinin bakım verenlerden farklı olduğunu bulmuşlardır (Demir ve 
ark, 2015). Ancak çalışmamızda cinsiyetin tedavi hedefleri açısından da önem taşıdığı görülmüştür. Aktivite hedefi uyumu düşük de olsa, kadın hastaların erkek hastalara göre bakım verenleriyle ortalamanın üzerinde bir uyuma sahip olduğu bulunmuştur. Bunun sebebinin toplumdaki kültürel çevrenin bir yansıması olabileceğini düşünmekteyiz. Bir kişinin aktivite seçimi, belirli aktiviteleri gerçekleştirmesi kültürel çevreden etkilenmektedir. Bu yüzden hastaların aktivite seçimlerinin kültürel yapısını keşfetmek önemlidir (Bette R. Bonder, Martin, \& Miracle, 2004). Hastalık sonrası bireylerin daha çok kendine bakım aktiviteleri ile uğraştıkları ve bu aktiviteleri hedef olarak belirttikleri ve toplumumuzda, üretkenliğe yönelik aktivitelerin daha çok erkekler tarafından gerçekleştirildiği göz önüne alındığında, erkek hastalar ve bakım verenleri arasındaki aktivite hedefi uyumunun daha düşük olması makul bir sonuçtur.

Nörolojik hastalıklara sahip hastalar ve bakım verenlerinin en çok kendine bakım performans alanında tedavi hedefleri belirttiği çalışmamız sonucunda görülmektedir. Tatlı ve Akel, inmeli bireylerle yaptıkları çalışmalarında bu bireylerin gün içerisinde en çok kendine bakım aktiviteleri ile uğraştıklarını belirtmişlerdir (Tatlı \& Akel, 2016). Kendine bakım aktiviteleri hayatın devamlılığı için temel aktivite alanlarındandır ve nörolojik hastalıklara sahip bireyler kendine bakım aktivitelerini oldukça önemli görmektedirler (Bette R Bonder \& Dal Bello-Haas, 2017; Tudor-Locke, Washington, Ainsworth, \& Troiano, 2009). Çalışmamızda da bu durumla paralel olarak hem hastaların hem de bakım verenlerin tedavi hedefleri olarak öncelikle yemek yemek, giyinmek ve banyo yapmak gibi kendine bakım aktivitelerini geliştirmek gerektiği görüşüne sahip oldukları görülmektedir.

Bakım verenler, hastaların tedavisinde hedef olarak kişisel bakım aktivitelerine ek olarak toplumla bütünleşmeyi ve toplumsal katılımı sağlayan sosyalizasyon aktiviteleri üzerinde durmaktadırlar ("Occupational Therapy Practice Framework: Domain and Process," 2014). Hastalar tedavi hedefi olarak serbest zaman aktivitelerinde sosyalizasyondan ziyade aktif rekreasyona yönelik hedefler belirtse de bakım verenlerin tedavi hedefleri hastaların sosyalizasyon aktivitelerinin etkilendiğini göstermektedir. Aile ve sosyal desteğin azalması bakım verenin yükünü de etkilemektedir (McCullagh, Brigstocke, Donaldson, \& Kalra, 2005). Ayrıca hastaların serbest zaman aktivitelerindeki çeşitliliğini azaltmakta ve toplumsal katılımlarına zarar vermektedir (Amarshi, Artero, \& Reid, 2006; Tatlı \&
Akel, 2016). Bundan dolayı bakım verenlerin, hastaların özellikle sosyalizasyona yönelik serbest zaman aktivitelerini geliştirmek üzere bir tedavi programını tercih ettiklerini ve böyle bir programın bakım verenlerin yükünü azaltacağını ve hastaların sosyal katılımını yeniden düzenleyeceğini düşünmekteyiz.

Nörolojik hastalıklara sahip hastaların en çok belirttiği beş aktivitenin kendine bakım ve üretkenlik aktivitelerinden oluştuğu ve serbest zaman aktivitelerini içermediği, bakım verenlerin en çok belirttiği beş aktivitenin ise serbest zaman ve kendine bakım aktivitelerinden oluştuğu ve üretkenlik aktivitelerini içermediği görülmektedir. Bundan dolayı rehabilitasyonda hastaların daha çok yaşamak için gerekli olan, ev içerisindeki günlük yaşamı destekleyen ve finansal desteği sağlayan temel intiyaçlara öncelik verdiği görülmektedir. Literatürde, hastalardaki işe dönüşün desteklenmesinin sağlık seviyesini artıracağı, iş aktivitelerinin bireyi üretken bir yapı haline getirdiği ve bu durumun finansal destek sonrası bireyin diğer aktivitelerini de olumlu etkilediği belirtilmiştir (Woodside, 1976; Yerxa, 1993). Çalışmamızdaki hastaların aktivite hedefleri arasında üretkenlik aktivitelerinin sıklıkla yer almasının sebebinin hastaların genç popülasyondan oluşmasından kaynaklandığını düşünmekteyiz.

Çalışmamıza katılan hastaların belirli bir hastalığa özgü olmaması, hastalıktan sonra geçen sürenin incelenmemesi ve bakım verenlerin cinsiyet ve eğitim düzeyinin araştırılmaması çalışmamızın limitasyonları arasında gösterilebilir. İleriki çalışmalarda spesifik hastalıklarda ve cinsiyet açısından hasta ve bakım verenin tedavi hedeflerinin incelenmesini önermekteyiz. Ayrıca bakım veren yükünü azaltmak amacıyla nörolojik hastalıklara sahip bireylerde sosyalizasyon aktivitelerinin gelişimini hedefleyen tedavi programlarının araştırılması gerektiğini düşünmekteyiz.

Çalışmamız sonucu, rehabilitasyonun hem hasta hem de bakım veren için olumlu ve tatminkâr sonuçlar vermesi açısından her iki grubun tedavi hedefleri arasındaki uyumun önemli olduğunu düşünmekteyiz. Bu uyumun artırılmasına yönelik literatürde 'görülmeyen ikincil hastalar' olarak tanımlanan ve hastaların yaşam kalitesinde önemli bir rolü olan bakım verenlerin rehabilitasyon sürecine dahil edilmesi önemlidir (Brodaty \& Donkin, 2009). Bakım verenin de tedaviye dahil edilerek, şekillendirilmiş rehabilitasyon programlarının oluşturulmasına önem verilmesi gerekmektedir. Ayrıca iyileşme sürecinde hastalara sosyalizasyon aktivitelerinin, bakım verenlere ise üretkenlik 
aktivitelerinin önemi anlatılmalıdır. Bunlar göz önüne alınarak oluşturulan kişi merkezli tedavi programlarının hem hastanın hem de bakım verenin yaşam kalitesini ve tedaviye yönelik motivasyonlarını artıracağına inanmaktayız. Bütün bunlardan dolayı sağlık profesyonelleri, bu bireylerin tedavi ve bakımlarında bütüncül bir yaklaşım uygulamalılardır. Bakım verenler de sürece dahil edilmeli ve bütün konularda hasta ve bakım verenin aynı fikirde olduğu varsayımında bulunulmamalıdır (Trail, Nelson, Van, Appel, \& Lai, 2004).

\section{Kaynaklar}

Aarli, J. A., Dua, T., Janca, A., \& Muscetta, A. (2006). Neurological disorders. Public Health Challenges. Geneva: World Health Organization.

Amarshi, F., Artero, L., \& Reid, D. (2006). Exploring social and leisure participation among stroke survivors: Part two. International Journal of Therapy and Rehabilitation, 13(5), 199-208. doi:10.12968/ijtr.2006.13.5.21376

Aoun, S. M., Bentley, B., Funk, L., Toye, C., Grande, G., \& Stajduhar, K. J. (2012). A 10-year literature review of family caregiving for motor neurone disease: Moving from caregiver burden studies to palliative care interventions. Palliative Medicine, 27(5), 437-446. doi:10.1177/0269216312455729

Bolmsjö, I., \& Hermerén, G. (2003). Conflicts of Interest: experiences of close relatives of patients suffering from amyotrophic lateral sclerosis. Nursing Ethics, 10(2), 186198. doi:10.1191/0969733003ne593oa

Bonder, B. R., \& Dal Bello-Haas, V. (2017). Functional performance in older adults: FA Davis.

Bonder, B. R., Martin, L., \& Miracle, A. W. (2004). Culture Emergent in Occupation. American Journal of Occupational Therapy, 58(2), 159-168. doi:10.5014/ajot.58.2.159

Brodaty, H., \& Donkin, M. (2009). Family caregivers of people with dementia. Dialogues in Clinical Neuroscience, 11(2), 217-228.

Demir, Y. P., Balci, N. Ç., Ünlüer, N. Ö., Uluğ, N., Dogru, E., Kilinç, M., . . Yilmaz, Ö. (2015). Three different points of view in stroke rehabilitation: patient, caregiver, and physiotherapist. Topics in Stroke Rehabilitation, 22(5), 377-385. doi:10.1179/1074935714Z.0000000042

Donnelly, C., Eng, J. J., Hall, J., Alford, L., Giachino, R., Norton, K., \& Kerr, D. S. (2004). Client-centred assessment and the identification of meaningful treatment goals for individuals with a spinal cord injury. Spinal Cord, 42(5), 302-307.

Gitlin, L. N., Corcoran, M., Winter, L., Boyce, A., \& Hauck, W. W. (2001). A Randomized, Controlled Trial of a Home Environmental InterventionEffect on Efficacy and Upset in Caregivers and on Daily Function of Persons With Dementia. Gerontologist, 41(1), 4-14. doi:10.1093/geront/41.1.4

Graff, M. J. L., Vernooij-Dassen, M. J. M., Zajec, J., OldeRikkert, M. G. M., Hoefnagels, W. H. L., \& Dekker, J. (2006). How can occupational therapy improve the daily performance and communication of an older patient with dementia and his primary caregiver?: A case study. Dementia, 5(4), 503-532. doi: $10.1177 / 1471301206069918$

Law, M., Baptiste, S., McColl, M., Opzoomer, A., Polatajko, H., \& Pollock, N. (1990). The Canadian Occupational Performance Measure: An Outcome Measure for Occupational Therapy. Canadian Journal of Occupational Therapy, $57(2)$

82-87. doi:doi:10.1177/000841749005700207

McCullagh, E., Brigstocke, G., Donaldson, N., \& Kalra, L. (2005). Determinants of Caregiving Burden and Quality of Life in Caregivers of Stroke Patients. Stroke, 36(10), 2181-2186. doi:10.1161/01.str.0000181755.23914.53

McMillan, T. M., \& Sparkes, C. (1999). Goal Planning and Neurorehabilitation: The Wolfson Neurorehabilitation Centre Approach. Neuropsychological Rehabilitation, 9(34), 241-251. doi:10.1080/096020199389356

Mitchell, L. A., Hirdes, J., Poss, J. W., Slegers-Boyd, C., Caldarelli, H., \& Martin, L. (2015). Informal caregivers of clients with neurological conditions: profiles, patterns and risk factors for distress from a home care prevalence study. BMC Health Services Research, 15, 350. doi:10.1186/s12913-015-1010-1

Occupational Therapy Practice Framework: Domain and Process. (2014). The American Journal of Occupational Therapy, 68, 1-48.

Sands, L. P., Ferreira, P., Stewart, A. L., Brod, M., \& Yaffe, K. (2004). What Explains Differences Between Dementia Patients' and Their Caregivers' Ratings of Patients' Quality of Life? The American Journal of Geriatric Psychiatry, 12(3), 272-280. doi:https://doi.org/10.1097/00019442-200405000-00006

Tatlı, İ. Y., \& Akel, B. S. (2016). Inmeli Bireylerde Temporal Aktivite Paterninin Incelenmesi. Hacettepe Üniversitesi, Ankara.

Trail, M., Nelson, N. D., Van, J. N., Appel, S. H., \& Lai, E. C. (2004). Major stressors facing patients with amyotrophic lateral sclerosis (ALS): a survey to identify their concerns and to compare with those of their caregivers. Amyotrophic Lateral Sclerosis and Other Motor Neuron Disorders, 5(1), 40-45. doi:10.1080/14660820310016075

Tudor-Locke, C., Washington, T. L., Ainsworth, B. E., \& Troiano, R. P. (2009). Linking the American Time Use Survey (ATUS) and the Compendium of Physical Activities: methods and rationale. J Phys Act Health, 6(3), 347-353.

Tuntland, H., Aaslund, M. K., Langeland, E., Espehaug, B., \& Kjeken, I. (2016). Psychometric properties of the Canadian Occupational Performance Measure in homedwelling older adults. Journal of Multidisciplinary Healthcare, 9, 411-423. doi:10.2147/JMDH.S113727

Woodside, H. (1976). Dimensions of the Occupational Behaviour Model. Canadian Journal of Occupational Therapy, 43(1), 11-14. doi: $10.1177 / 000841747604300103$

Yerxa, E. J. (1993). Occupational science: A new source of power for participants in occupational therapy. Journal of Occupational Science, 1(1), 3-9. 